CLINICAL ETHICS

\title{
Demanding pure motives for donation: the moral acceptability of blood donations by haemochromatosis patients
}

\section{G Pennings}

J Med Ethics 2005;31:69-72. doi: 10.1136/jme.2002.001271

Correspondence to:

Dr G Pennings, Ghent

University, Centre for

Environmental Philosophy

and Bioethics, Department

of Philosophy,

Blandijnberg 2, B-9000

Ghent, Belgium; Guido.

Pennings@UGent.be

Received 31 July 2002

In revised form

30 January 2003

Accepted for publication

4 February 2003

\begin{abstract}
Blood banks all over the world attempt to cover the demand for blood by donations from voluntary nonremunerated donors. The discussion regarding the acceptability of blood donations by haemochromatosis patients focuses on the question of whether health benefits violate the rule of the altruistic donor. Utilitarian and deontological arguments for and against the policy of accepting blood donors who need to let blood regularly in order to stay healthy are considered by this article. A closer look at the procedure reveals that the confusion is due to the conflation of, on the one hand the phlebotomy, and on the other hand, the decision about the destination of the blood afterwards. The health benefits are connected to the phlebotomy and not to the donation. The morally relevant point in the decision as to whether the candidate is a truly altruistic donor is whether he donates without asking for a benefit in return. It is concluded that haemochromatosis patients can be free, voluntary, and altruistic blood donors.
\end{abstract}

A lthough there is a general consensus among the major societies involved in blood collection that no payment should be provided for blood donations, articles in which this rule is questioned surface with some regularity. Mostly this suggestion is triggered by the never ending battle to obtain enough material to cover the demand. Every effort is made to recruit a sufficient number of donors. The perpetual shortage makes it all the more incomprehensible when a perfectly suitable group is rejected as candidate donor. This is what it looks like to some people when patients who need therapeutic phlebotomies are refused as donors. The discussion is focused on the refusal of blood from haemochromatosis patients. Hereditary haemochromatosis is the most common autosomal recessive disease in the white population. The heterozygote prevalence ranges between $6 \%$ and $10 \%$ of the population in Europe and the United States. For the United States, this amounts to roughly one million people who are homozygous. When present in homozygous state, it leads to the accumulation of high amounts of iron in the body and lesions in the liver, heart, endocrine organs, and joints. Early detection and treatment can prevent the development of cirrhosis, impotence, heart failure, and other diseases. The primary treatment consists of periodic bleeding. Although the estimations of the number of possible blood units that individuals with haemochromatosis might contribute differs considerably, the acceptance of haemochromatosis patients could generate a substantial increase in the supply of blood. ${ }^{23}$

In recent years the discussion has shifted into higher gear. The position of major players in the field has undergone a rapid evolution. In 1999, the Food and Drug Administration in the United States dropped the request to attach a special label to the bags of blood from haemochromatosis patients. This request, which marked the blood as originating from a non-altruistic donor, was the main obstruction to the use of the blood for allogeneic transfusion. Also the Health Council of the Netherlands ${ }^{4}$ urged the government to reconsider the ban on haemochromatosis patients as blood donors. The
Council on Scientific Affairs of the American Medical Association $^{5}$ on the contrary spoke against the use of this blood for direct transfusion under the present circumstances. The main reason for rejecting these patients as donors is that they cannot be considered as altruistically motivated. The question, however, is whether health benefits constitute an infringement of the rule of the altruistic donor.

Two arguments are advanced to defend the rejection of blood withdrawn to promote the health of the donor: a consequentialist argument to do with the protection of the quality of the blood supply and a deontological argument which insists on the right motive for the donation.

\section{THE SAFETY OF THE BLOOD SUPPLY}

There are no indications that the blood of asymptomatic individuals with haemochromatosis poses a risk for the health of the recipients. It has even been suggested that their blood is better because it contains more young cells. ${ }^{6}$ If indeed this blood would be of a lesser quality than the blood obtained from other donors, the only acceptable solution would be to screen all donors for haemochromatosis. No screening takes place at present and no one has proposed such screening to improve blood quality. Several surveys have shown that a large percentage of the people diagnosed with haemochromatosis already served as blood donors before they were informed of their illness. ${ }^{78}$ This demonstrates that they meet the same donor suitability requirements as the normal population of blood donors.

The danger for the safety of the blood supply is generated by the indirect link with the motivation of the donor. In general, people who stand to benefit from giving blood have blood of a lesser quality; it contains more blood transfusion transmittable viruses (such as hepatitis B and C and HIV) than the blood of voluntary donors. When a comparison is made between non-paid and paid donors, the latter score systematically worse. ${ }^{9}$ One assumes that the explanation must be sought in the fact that paid donors hide information about risk behaviour for infectious diseases and medical 
history. This has never been demonstrated; it may be that people who donate for money have lower access to medical care or have a less healthy diet. Nevertheless, anecdotal evidence points in the direction of deliberate withholding of information. ${ }^{5}$

For the protection of the blood safety, the term "benefit" should be considered broadly. "Benefit" is any form of reward that might tempt the candidate donor to hide information. In one case discussed in the literature, the free day the donor received from his employer was sufficient reason for lying about risk behaviour for AIDS. ${ }^{10}$ Whatever the explanation of the difference between paid and non-paid donors, if we take into account a "window" period during which the infection cannot be detected, the rate of errors which inevitably are present in all tests, and the possibility of new and unknown viruses, it can be concluded that the blood of remunerated donors holds more risk for the recipients.

The benefits for haemochromatosis patients who are accepted as regular blood donors are twofold: the cost reduction and the health benefit.

\subsection{The cost reduction}

The healthcare system of the country in which the patients live determines whether they have to pay for the phlebotomies they have to undergo. The financial cost, especially when health insurance is not available for everyone, may be substantial. Since phlebotomy for blood donation is free, haemochromatosis patients enjoy a considerable cost reduction by becoming blood donors. In countries such as the United Kingdom where phlebotomy is covered by the National Health Service (NHS), this benefit does not apply as there are no financial costs for the patients in the first place. In most European countries, the largest part of the costs is reimbursed by health insurance but the remaining out of pocket costs may, given the high frequency of phlebotomies needed, still be considered as unacceptably high by some patients. Beside the financial costs, several practical costs (waiting time, doctor visits, transport, and so on) should be included. The obvious way to eliminate financial incentives to seek blood donation for purposes of phlebotomy is the removal of the benefit by making all phlebotomies free. This implies complete reimbursement of all phlebotomies even for people who do no want to donate or whose blood is not suitable for donation. The acceptability of this solution depends partially on the degree to which we need the blood and thus on the shortage of blood donors. The American Medical Association and the Food and Drug Administration present the free of charge phlebotomy as a necessary condition for the acceptance of haemochromatosis patients. In countries such as Canada, Australia, and Sweden, where these patients are already accepted as blood donors, this measure was implemented before this group was accepted. ${ }^{11}$

\subsection{The health benefit}

According to the opponents of haemochromatosis patients as donors, people who donate for therapeutic reasons cannot be considered as purely altruistic donors because they have a self serving goal-that is, their health. Moreover, they are not free to donate since phlebotomies are the most effective (and most cost effective) method of reducing the iron overload. Two general remarks may illustrate the difficulty of maintaining the categorical rejection of candidates whose health benefits by the blood donation. Firstly, recent medical articles suggest that regular blood donation may decrease the risk of heart attacks and cardiovascular diseases due to the lower iron levels in the body of blood donors. ${ }^{12}{ }^{13}$ Assume for a moment that this information is confirmed and that the population is informed of this fact. From that moment onwards, we can no longer be sure that candidate donors are not motivated more by the health benefits than by the wish to help others. If we want to maintain the strict standard of altruism, we would have to refuse all candidates who belong to the groups whose health would most benefit by the donations and those most prone to heart attacks.

Secondly, the disease itself has no impact on the qualification of the candidate donor (at least as long as he is healthy and asymptomatic). The danger lies in the knowledge that the donor has of her disease status. Only people who have been diagnosed as homozygotic for haemochromatosis can be motivated by the therapeutic advantage. Ignorance gives a pure soul. The more people there are who know their status, the more people will have to be rejected as blood donors. Although it could be argued that haemochromatosis is a prime target for screening (high prevalence, morbidity, and mortality, and benefit of early diagnosis and treatment), ${ }^{14}{ }^{15}$ population screening would lead to a rejection of all persons identified as haemochromatosis patients.

\section{THE RULE OF ALTRUISTIC MOTIVATION}

The demand for the right motivation fits with the general moral principle that a helping act only has moral value when it is made for an altruistic reason. ${ }^{16}$ The distinction between a helping act and morally praiseworthy helping behaviour is made by several philosophers, going from Kant to Nagel to Blum. ${ }^{17}$ This position rejects the utilitarian point of view in which motives play at most an indirect role and helping behaviour is justified by the contribution to the welfare of the recipients. The deontological position focuses mainly on the reason for performing the act. The specificity of this approach can be demonstrated by imagining that major improvements in the effectiveness of the virus inactivation methods would virtually eliminate the risk of transmission of major known pathogens, just as is presently the case for blood plasma. Although such methods would emasculate the safety argument against paid or remunerated donors, the deontological argument would remain in force. We do not just want blood, we want altruistically donated blood.

There are a large number of reasons for rejecting paid donation besides the fact that it is selfish and has no moral value. Broad societal and ethical effects of payment such as the commercialisation of the body and the exploitation of the poor members of society may constitute more powerful arguments. ${ }^{18} 19$ A donation that is motivated by health benefits is not, however, contrary to the background theories on the nature of society, the special status of the human body, and theories of human motivation. Nor does it generate the undesirable consequences which follow the introduction of payment as an incentive. The acceptance of blood from haemochromatosis patients who need therapeutic phlebotomies does not lead to the hegemony of the market as the sole structure of interaction between people and does not lead to impersonal and alienating relationships. It is also unlikely that accepting the blood of these people will have a discouraging effect on the purely altruistic donor. The disease is not a self chosen condition and presents neither an alternative nor a temptation for the normal blood donor. I will not argue, however, that health benefits do not contradict the altruism rule. I will show that the health benefits have nothing to do with the donation itself.

\section{SEPARATING PHLEBOTOMY AND BLOOD DONATION}

The procedure should be divided into two parts: the physical intervention (the phlebotomy, the taking of the blood) and the decision regarding the disposition of the blood that is obtained. The relevance of the dual structure is made clear 
when we consider the practice of autologous transfusions Autologous transfusions have increased enormously, mainly motivated by the fear for HIV infection. People who need to undergo surgery or other procedures during which they will probably need a blood transfusion, can present in the weeks preceding the operation for blood letting. They have their own blood stored for the specific purpose of transfusion during the operation. Research has shown, however, that the practice is very wasteful because a lot of the stored blood is never used for those who have stored it. The question arose whether this blood could be donated for transfusion of others. The dual structure is revealed in this practice: there is a physical intervention followed by a decision about the disposition of the blood that is obtained. It is remarkable that the Council on Scientific Affairs for the American Medical Association, which rejected the use of blood from haemochromatosis patients for allogeneic donation because of the inappropriate motivation of the donors, does not refer to the motivation of the store givers to reject the use of blood originally meant for autologous transfusion. ${ }^{20}$ This "crossover" from autologous to allogeneic use is at present rejected mainly because of the low cost effectiveness and because of the higher risk of contamination. If, however, the same standard is used as for haemochromatosis patients, one should question the acceptability of the motivation as this blood was originally not taken for altruistic reasons.

People may have various reasons for submitting to a phlebotomy. Blood can be let to improve or maintain one's health, to sell, to store for one's own use, or to donate. The arguments against the acceptance of haemochromatosis patients as blood donors are directed at the fact that they do not undergo the phlebotomy with the intention to donate. The requirement of pure motives is, however, focused on the wrong part of the procedure. The motive for the phlebotomy does not have to coincide with the motive for the donation. A person is motivated by selfish motives when he donates his blood for transfusion by others in return for a personal benefit. Haemochromatosis patients do not voluntarily and freely present for the phlebotomy but they can voluntarily and freely donate their blood afterwards. In fact, the patients no longer enjoy any advantage from being accepted as a blood donor and from donating their blood. If they do not feel motivated by altruism or social concerns, they can simply let the blood be destroyed.

The identification of the physical intervention and the decision about the disposition is expressed in the terminology. Some authors use the expression "autologous donations" when no donation is involved but only storage. ${ }^{21}$ The term "donation" is currently employed to cover both parts of the procedure. This is of course due to the simple fact that in normal circumstances one cannot donate without submitting to a phlebotomy. In current practice, policy makers not only demand an altruistic motivation for the donation but also for the phlebotomy.

\section{COSTS, SACRIFICE, AND ALTRUISTIC BEHAVIOUR}

The attitude towards patients who need therapeutic phlebotomy assumes that donors have to incur costs (in the broad sense of the term) and have to suffer some inconvenience in order to be able to donate altruistically. Although altruism frequently implies a form of sacrifice, this is not necessary. ${ }^{22}$ It is one thing to value a helping act more when the helper has to make large sacrifices to help; it is quite another to value an act only when the act goes against the self interest of the helper. Consider the situation where the car of person $\mathrm{Y}$ breaks down and he tries to catch a ride. Person $X$ stops and takes Y with him to a service station which is on X's way. The costs for $X$ are minimal since he had to pass that service station anyway. Nevertheless, $\mathrm{X}^{\prime} \mathrm{s}$ act is generally considered as a helping and other regarding act. $\mathrm{X}$ did stop and took $\mathrm{Y}$ to the service station with the intention to help Y. We generally consider $\mathrm{X}$ as a friendly and helping person and the act as praiseworthy (be it to a rather limited degree). If we did not praise $X$, he would be punished (in a sense) for the fact that he had to go in that direction. This would be the conclusion if we extend this reasoning to blood donation by haemochromatosis patients: they submit to the phlebotomy which they need to have anyway. That part of the effort, which in normal circumstances is performed for the purpose of donation, is in their case not specifically done for that goal. Statements by patients indicate that they consider their rejection as blood donors as unjust punishment for something they cannot do anything about. This is especially difficult to swallow for patients who already served as blood donors before the diagnosis of haemochromatosis was made. These patients consider the refusal to use their blood as a complete and unjustified waste of valuable resources. ${ }^{23}$ A number of these patients are highly motivated to donate and the experience of this "waste" is a sufficient reason for some to lie to the blood bank about their illness. ${ }^{24}$

The costs and efforts of the helping behaviour for the helper play a role in the evaluation of the act. The ethical discussion on the Good Samaritan laws showed that there is only a duty to help when the person can help with very little (or no) costs to himself. ${ }^{25}$ The costs, if sufficiently high, justify a person's refusal to help. Ironically, it could be argued that the haemochromatosis patient, by already submitting to the venepuncture, has lost the most important excuse for not donating blood. In general the duty to benefit becomes stronger the higher the advantages for the recipient and the lower the costs for the helper. ${ }^{26}$ A person is considered more praiseworthy and more virtuous when he is prepared to make those costs to benefit others. We do not, however, design the donation procedure to test the virtue of the people. If we can decrease the costs in terms of time, effort, or pain by redesigning the guidelines of the donation procedure, we are morally obliged to do so. If the costs decrease for a certain group as a consequence of the circumstances, then this should be considered a lucky coincidence. We should look at the blood donation of people who need phlebotomy for their health as a win-win situation. ${ }^{27}$ Moreover, the presentation mentioned above starts from the presumption that the venepuncture (together with the time and travel to donate, the pain and inconvenience, and the psychological resistance to the puncture) is the major cost. Since the donor undergoes all these disadvantages for the phlebotomy, the donation itself would be completely without costs. This view, however, ignores the psychological and symbolic meaning of the donation. That meaning is part of the recruitment campaigns for blood donors and is partially expressed in the link between donating blood and preserving life. The symbolic significance of sharing the same blood is also expressed in the importance attributed to the blood link. The same attitude towards organ donation after death would imply that the only cost for the donor is to sign the consent form. If this were indeed the only effort required, the low number of organ donors after death would be a real mystery. It would in this respect be interesting to look more closely at the reasons haemochromatosis patients give for not donating their blood when they fulfil the medical conditions to become blood donors.

\section{CONCLUSION}

Patients with haemochromatosis receive two benefits when they get accepted as blood donors: they do not have to pay for the blood letting and they remain healthy. In order to prevent haemochromatosis patients from being tempted to withhold relevant medical information from the blood bank in order to 
be accepted as donors, the system should be adapted so that no patient is charged for therapeutic phlebotomy. The belief that the health benefit jeopardises the altruistic nature of the act is largely based on a confusion between the phlebotomy and the disposition of the blood. Haemochromatosis patients have a need for blood letting but they are free to decide what should be done with the blood. They do not receive any reward or benefit by donating the blood rather than destroying it. Consequently, haemochromatosis patients can be free, voluntary, and altruistic donors. The moral question that should concern the policy makers is whether the donation of the blood, and not the phlebotomy, is performed for altruistic reasons.

Research for this article was made possible by grant G.0065.00 from the Fund for Scientific Research-Flanders, Belgium.

\section{REFERENCES}

1 Barash $\mathrm{Cl}$. Genetic discrimination and screening for hemochromatosis: then and now. Genet Test 2000;4:213-18.

2 Grindon A. Perspectives on blood donation by individuals with hemochromatosis. Eighth Meeting of the US Public Health Service, Advisory Committee on Blood Safety and Availability: The Reserve Capacity of the Nation's Blood Supply; 1999 Apr 30; Bethesda, MD http://www.hhs.gov/ bloodsafety/transcripts/19990430.html (accessed 2 June 2004).

3 Jeffrey G, Adams PC. Blood from patients with hereditary hemochromatosis a wasted resource? Transfusion 1999:39:549-50.

4 Health Council of the Netherlands. Screening for haemochromatosis. The Hague: Health Council of the Netherlands, publication no 1999/21, 1999.

5 Tan L, Khan MK, Hawk III JC, for the Council on Scientific Affairs, American Medical Association. Use of blood therapeutically drawn from hemochromatosis patients. Transfusion 1999:39:1018-26.

6 American Association of Blood Banks. Blood donors and hemochromatosis: questions and answers. http://www.aabb.org/members_only/ archives071300/association_bulletins/ab00-2.htm (accessed 20 July 2000).

7 Barton JC, Grindon AJ, Barton NH, et al. Hemochromatosis probands as blood donors. Transfusion 1999;39:578-85.

8 McDonnell SM, Grindon AJ, Preston BL, et al. A survey of phlebotomy among persons with hemochromatosis. Transfusion 1999;39:651-6.
9 Eastlund T. Monetary blood donation incentives and the risk of transfusion transmitted infection. Transfusion 1998;38:874-82.

10 McFarland JG, Aster RH, Buggy BP. Paid time off for blood donation-an incentive to be less than truthful? Transfusion 1997:37:447-8.

11 Sacher RA. Hemochromatosis and blood donors: a perspective. Transfusion 1999;39:551-4.

12 Meyers DG, Strickland D, Maloley PA, et al. Possible association of a reduction in cardiovascular events with blood donation. Heart 1997:78:188-93.

13 Salonen JT, Tuomainen T-P, Salonen R, et al. Donation of blood is associated with reduced risk of myocardial infarction. Am J Epidemiol 1998;148:445-51.

14 Adams PC, Valberg LS. Screening blood donors for hereditary hemochromatosis: decision analysis model comparing genotyping to phenotyping. Am J Gastroenterol 1999;94:1593-600.

15 Allen K, Williamson R. Should we genetically test everyone for haemochromatosis? J Med Ethics 1999;25:209-14

16 Kekes J. Morality and altruism. J Value Inq 1981;15:265-78

17 Campbell J. Can philosophical accounts of altruism accommodate experimental data on helping behaviour? Australas J Philos 1999:77:26-45.

18 Beal RW, Van Aken WG. Gift or good? A contemporary examination of the voluntary and commercial aspects of blood donation. Vox Sang 1992;63:1-5.

19 Keown J. The gift of blood in Europe: an ethical defence of EC directive 89/381. J Med Ethics 1997;23:96-100.

20 Blum LN, Allen JR, Genel M, et al. Crossover use of donated blood for autologous transfusion: report of the Council on Scientific Affairs, American Medical Association. Transfusion 1998;38:891-5.

21 Thomas MJG, Desmond M, Gillon J. Preoperative autologous donation: what was the impact on the 1995 consensus statement? Transfus Med 1999;9:241-57.

22 Schmidtz D. Reasons for altruism. Soc Philos Policy 1993; 10:52-68.

23 Blacklock HA, Dewse M, Bolard C, et al. Blood donation by healthy individuals with haemochromatosis. N Z Med J 2000;1 13:77-8.

24 Hawkins D. Throwing out good blood. US News Online 1 Sept 1997. http://www.usnews.com/usnews/issue/970901/1 bloo.html laccessed 20 July 2000).

25 Kamm FM. Supererogation and obligation. J Philos 1985;82:118-38.

26 Beauchamp TL, Childress JF, eds. Principles of biomedical ethics. New York, Oxford: Oxford University Press, 1989.

27 Penning HL. Blood donation by patients with hemochromatosis. JAMA 1993;270:2929. 